\title{
Las causas psicológicas del cosmopolitismo y del nacionalismo. ¿Los míos en pro o en contra de los otros?
}

\section{Mariela Andrea Mesa Suárez ${ }^{*}$}

\section{RESUMEN}

Cosmopolitismo y nacionalismo son visiones esenciales y complementarias del mundo. Un individuo no puede prescindir conscientemente de ninguna de ellas, si desea desenvolverse naturalmente en un mundo globalizado, pero con altos matices que exigen una identidad cultural. Estas dos posturas, cosmopolitismo y nacionalismo, se necesitan el uno a la otra para garantizar una sana psiquis individual y colectiva. El objetivo del presente artículo es mostrar que el individuo y las colectividades, bien sean naciones, Estados, Estados-nación o "naciones sin Estado", para lograr interpretar y adaptarse al mundo actual tienen necesidades psicológicas, tanto de posturas nacionalistas como cosmopolitas y ambas coexisten en la vida cotidiana.

Palabras clave: complementariedad, nacionalismo y cosmopolitismo; psicología de grupos, psicoanálisis-nacionalismo, psicoanálisis-cosmopolitismo, educación.

\section{The psychological causes of cosmopolitism and nationalism. Ours in pro or against others?}

* Economista, doctora en estudios políticos y magíster en gobierno y políticas públicas de la Universidad Externado de Colombia. Especialista en evaluación de proyectos de la Universidad de los Andes. Docente de la Universidad Externado de Colombia. Bogotá (Colombia). [mariela.mesa@uexternado.edu.co].

Recibido: 30 de marzo de 2018 / Modificado: 17 de junio de 2018 / Aceptado: 18 de junio de 2018.

Para citar este artículo:

Mesa Suárez, M. A. (2018). Las causas psicológicas del cosmopolitismo y del nacionalismo. ¿Los míos en pro o en contra de los otros? OASIS, 28, pp. 65-81.

DOI: https://doi.org/10.18601/16577558.n28.05 


\section{ABSTRACT}

Cosmopolitanism and nationalism are both essential and complementary world views. An individual cannot prescind from any of them consciously if they wish to naturally manage themselves in a globalized world, taking also into account the important nuances required by cultural identity. These two positions (views), cosmopolitanism and nationalism need one another in order to ensure a healthy individual and collective psyche. The objective of this article is to show that psychologically, the individual and the collectivities (nations, states, nation-states, "nations without state") have both nationalist and cosmopolitains needs, in order to achieve a proper adaptation and interpretation of the current world.

Key words: Complementarity, nationalism and cosmopolitanism, group psychology, psychoanalysis - nationalism, psychoanalysis cosmopolitanism, education.

El cosmopolitismo y el nacionalismo son lecturas complementarias de las mismas realidades. Renunciar a alguna de las dos visiones, desde el punto de vista del individuo y de las comunidades, puede ser nocivo para la propia identidad o para la incorporación a un mundo que cada vez exige más afinidad con ámbitos interculturales. Antes de seguir adelante es importante anotar que en este artículo se entiende por comunidades o colectividades lo que en teoría de relaciones internacionales se denomina nación, Estado, Estado-nación o nación sin Estado, y se recurrirá a la diferenciación que la autora catalana y catedrática de Queen
Mary, Monserrat Guibernau, y la psicóloga especialista en ciencias del comportamiento, Rosa María Núñez, hacen de estos términos.

Ellas evocan la noción weberiana del Estado como comunidad humana que, exitosamente, hace uso efectivo de un territorio mediante el empleo legítimo de la fuerza física; por nación hacen referencia a grupos de personas que, además de compartir, de forma no específica, un origen y muchos vínculos de carácter cultural, histórico y territorial, tienen en común exigencias políticas específicas, y consideran los Estados-nación

un fenómeno moderno, caracterizado por la formación de un tipo de Estado que tiene el monopolio de lo que reclama como uso legítimo de la fuerza en un territorio delimitado, y trata de unir a personas sujetas a su gobierno mediante la homogenización, creando una cultura, símbolos y valores comunes, reviviendo tradiciones y mitos de origen y en ocasiones, inventándolos [...] Mientras que las personas que forman una nación tienen un sentido de la patria y sienten apego a un territorio, el Estado nación puede ser resultado de un tratado, o de la voluntad de políticos que deciden cuándo trazar una línea entre Estados (Guibernau y Núñez, 1998, pp. 115-116).

En otras palabras, los habitantes de una nación comparten, de manera natural, elementos culturales, valores y símbolos, mientras que estos aspectos en un Estado-nación son un invento político que sirve de base para su creación. Finalmente, para Guibernau y Núñez las naciones sin Estado son aquellas comunidades que, aunque carecen de instituciones políticas propias, tienen una conciencia de grupo, comparten unos lazos étnicos, valores, elementos 
culturales y, probablemente, un idioma o dialecto. Y dichos lazos se extienden entre ellas con diferentes grados de cohesión.

En la teoría freudiana todo acto de agresión está ligado a uno de amor. Podría pensarse entonces que en la psiquis individual y colectiva, todo sentimiento cosmopolita está atado por contraposición o cohesión a uno nacionalista. En términos psicoanalíticos lo masculino corresponde al nacionalismo y se lee en lo positivo o instinto de vida, y lo femenino, negativo o pulsión de muerte se advierte en el cosmopolitismo. Julia Kristeva, francesa de origen búlgaro, e Isabel Vericat, al respecto dicen:

En el rechazo fascinado que suscita en nosotros lo extranjero hay una parte de inquietante extrañeza en el sentido de la despersonalización que Freud descubrió en ella y que se reanuda con nuestros deseos y nuestros miedos infantiles al otro, el otro de la muerte, el otro de la mujer, el otro de la pulsión indomeñable. Lo extranjero está en nosotros. Y cuando huimos o combatimos al extranjero, luchamos contra nuestro inconsciente, este -impropio- de nuestro -propioimposible" (Kristeva y Vericat, 1996, p. 367).

Resulta interesante cómo estas dos autoras reconocen la identificación y correspondiente rechazo que los otros producen en nosotros; justamente aquello que tanto criticamos, que tanto nos molesta es aquella parte que proyectamos en los otros y no somos capaces de aceptar en nosotros. Esta observación es ejemplificada por Bernardo Subercaseaux, con algunas conductas que repugnamos en nosotros y por ello se las atribuimos a los otros:
Lo femenino era lo foráneo, la oligarquía afrancesada, el ocio, la especulación, la raza latina, los inmigrantes, el modernismo y las poéticas cosmopolitas, el parlamentarismo ineficiente, la belle époque criolla, los juegos de azar y los políticos pusilánimes. [Por el contrario, este mismo autor afirma que lo masculino, le ha sido atribuido al nacionalismo en el imaginario colectivo:] lo masculino en cambio correspondía a la industria, al espíritu emprendedor y guerrero [...] a la ciencia, a la literatura que no fuera escapista, que se hiciera cargo de la realidad y desnudara las apariencias (Subercaseaux, 1993, p. 248).

Podría entonces establecerse una analogía: para que exista la luz debe haber oscuridad, y al jugar juntas forman sombras. Lo positivo requiere de la existencia de lo negativo. Lo masculino y lo femenino se oponen y se atraen. El nacionalismo y el cosmopolitismo se repelen, pero se aceptan y cuando se interceptan se complementan.

El presente artículo se divide en tres secciones: en la primera se profundiza en lo que aquí se denominan "las causas naturales del nacionalismo" y corresponde a necesidades psicológicas que pueden ser satisfechas con las posturas nacionalistas; en la segunda se hace lo propio con el cosmopolitismo, es decir, se indaga en las exigencias psicológicas del individuo que son suplidas por visiones más cosmopolitas. Estas dos secciones se irán ilustrando con ejemplos de colectividades o lo que Guibernau (1998) denomina las cinco dimensiones psicológicas de una nación: coincidencia de formar un grupo, cultura, territorio, política e historia, así como con representaciones de visiones más cosmopolitas de las colectividades. En la 
tercera sección, y a manera de conclusión, se presenta un recuento de ambos tipos de necesidades enfatizando en su complementariedad.

\section{LAS CAUSAS NATURALES DEL NACIONALISMO}

El artículo What can examining the Psychology of Nationalism Tell Us About Our Prospects for Aiming de Gillian Brock y Quentin Adquinson (2008), sirvió como materia prima para el presente apartado, pues proporciona una síntesis de la literatura de la dinámica de los grupos y sus prejuicios. Estos autores encuentran una serie de argumentos que desde el punto de vista psicológico pueden justificar el nacionalismo. El artículo originalmente se proponía analizar las causas psicológicas del nacionalismo que han tendido a dominar el cosmopolitismo, y sus argumentos han permitido que la literatura se incline por tildar el nacionalismo como irrealista e inaplicable.

En este orden de ideas, Brock y Adquinson (2008) sostienen que el cosmopolitismo no es antiético con dichas causas psicológicas del nacionalismo y proponen algunas medidas prácticas, para hacer del cosmopolitismo una postura más viable. Debe advertirse que mucha de la bibliografía que ellos citan o referencian ha sido tenida en cuenta en este artículo, sin consultar la fuente original, en algunos casos porque la antigüedad del documento no lo permitía y en otras porque se trataba solo de elementos para ampliar un argumento ${ }^{1}$.
Entre los argumentos que, desde el punto de vista psicológico pueden justificar el nacionalismo, Brock y Atkinson (2008) mencionan el que aquí se denomina "El favoritismo por los míos" y que corresponde al hallazgo de Tajfel, Flament, Biling y Bundy (1971), según el cual "las personas tienden a calificar a los miembros de su propio grupo como más agradables, inteligentes y confiables que a miembros de otros grupos”, de hecho esto puede conllevar, según Brock y Atkinson, a la hostilidad hacia todos aquellos que no sean del grupo. Más aún, el favoritismo por los del grupo o por "los míos", puede encontrar explicación en la necesidad de maximizar las propias ganancias.

Para ejemplificar esto en la historia mundial, basta con ubicarse en 1947, cuando el subcontinente de la India se independizó de Gran Bretaña, dividiéndose en la República Islámica de Pakistán, esencialmente musulmana, y la República de la India, básicamente hinduista; además de tener religiones muy diferentes estos dos países incorporaban grupos raciales muy diversos. Era evidente que a lo largo de las fronteras existía un "favoritismo por los míos" del otro país. De esta manera, en Pakistán occidental se encontraban los punyab, muy afines por su tradición y cultura con los persas, y en Pakistán oriental los bengalí, mucho más emparentados con el hinduismo. Las preferencias de la India se develaron cuando en 1971 la población bengalí se reveló contra el Estado de Pakistán por no atender sus demandas; en ese momento sus congéneres de la India

1 En las referencias bibliográficas se hará una diferenciación de los textos estudiados por la autora de este trabajo y los que no, pues más allá de la rigidez metodológica, pueden ser de interés para quien desee profundizar en el tema. 
manifestaron su "preferencia por los propios" del Estado pakistaní y apoyaron a los bengalíes, el levantamiento fue en escalada y se convirtió en una guerra entre India y Pakistán, que dejó a este último como perdedor teniendo que renunciar a Pakistán oriental, que actualmente se conoce como el Estado de Bangladesh.

De este acontecimiento de historia internacional, la guerra entre Pakistán y la India, que aquí se utiliza para ejemplificar una de las necesidades psicológicas del individuo desde el punto de vista colectivo, y que está estrechamente asociada al nacionalismo, "el favoritismo hacia los míos", se puede derivar la distinción de dos conceptos importantes: "el comportamiento de política exterior" y la “política exterior”. El primero

se relaciona con las decisiones que toman los Estados entre sí. La formación de alianzas es un tipo de comportamiento o política exterior [mientras que] la política exterior se refiere al conjunto de prioridades o preceptos establecidos por los líderes nacionales para servir como líneas de conducta entre diversos cursos de acción, en situaciones específicas y dentro de contextos de lucha por alcanzar sus metas (Pearson y Rochester, 2004, p. 113).

De esta manera, el comportamiento de política exterior de la India fue proporcionar ayuda externa a sus semejantes bengalíes, con la aspiración a largo plazo o como política exterior de debilitar a Pakistán y ganar protagonismo en Asia meridional.

Tal como se evidencia en el ejemplo anterior, el "favoritismo hacía los míos" puede tornar peor la competencia por el uso de un recurso, según The realistic conflict theory - RCT
(Sherif, 1966, citada por Brock y Atkinson, 2008), es decir, se puede tornar en enemistad e intolerancia con los otros (el estallido de una guerra); pero también puede incrementar la cohesión entre los del mismo grupo (los bengalíes conformaron el Estado de Bangladesh). Lo que se denomina el "favoritismo hacia los míos”, el nacionalismo sería, a su vez, una causa y una consecuencia de la lucha por los recursos escasos como el territorio, en este caso el antiguo Pakistán oriental.

Otro ejemplo de cómo "el favoritismo hacia los míos" se puede tornar en hostilidad hacia los otros es el liberalismo contemporáneo, que según Sedinger (2002, p. 64): "En sus esfuerzos por erradicar el antagonismo político y el conflicto del espacio social, [...] impone una homogeneidad formal en diferentes colectivos, transformándolos en competidores (en sentido económico) para la distribución de bienes sociales y económicos [... mediando] entre diferentes grupos de interés, todos los cuales se reducen a la misma forma”, a la misma identidad.

La necesidad de la autoestima y automejoramiento es otra causa psicológica del nacionalismo citada por Brock y Atkinson (2008), refiriendo a la teoría de la identidad social de Tajfel y Turner (1979), que sostiene que existen dos componentes de nuestra identidad, uno individual y otro social. Según estos últimos, un individuo se suscribe a un grupo para mejorar su autoestima, en otras palabras, para satisfacer su necesidad de esta los individuos utilizan vías grupales. Las filiaciones permiten a las personas proyectar sus propios sentimientos negativos en grupos que consideran inferiores, estableciendo una comparación inconsciente 
frente a sus miembros, respecto a los cuales se sienten superiores.

Un ejemplo claro de ello es la nación sin Estado -cuya definición se brindó al principio del artículo-, como Cataluña, una comunidad autónoma de la España posterior al franquismo, que gozaba de cierta autonomía estatal hasta ser intervenida recientemente por el gobierno central español. Cataluña poseía parlamento propio, gobierno y presidente local, y podía decidir con independencia del gobierno central. Esta comunidad autónoma ejemplifica la autoestima y automejoramiento llevado a un colectivo nacionalista. El cataluñismo siempre ha existido, sin embargo, sus ansias de independencia parecen haberse atizado desde 2006, y en estos momentos está pasando por un fuerte frenazo que ha conducido a que el Partido Popular español (que tradicionalmente se ha opuesto a la separación de esta comunidad autónoma), haya influido para que el ex presidente de Cataluña, Carles Puigdemont, fuera detenido en Alemania acusado por los delitos de sedición, rebelión y malversación de fondos; trasgresiones que parecen haber sido descalificadas por el gobierno alemán.

A los catalanes los une un territorio, un dialecto común (el catalán), el amor por el Barça y por su mar, unas costumbres, unos valores que los hacen proyectar en los otros (resto de España o más bien los unionistas) sus propios sentimientos negativos que los llevan a desear tener sus propias organizaciones gubernamentales aún más diferenciadas, lo que puede ser una explicación al hecho de que esta nación sin Estado haya tratado varias veces de emanciparse de la madre patria.
Respecto de este punto, Horney (1993, p. 105) anota que el afán de prestigio de las personas y su inclinación a humillar a quienes consideran inferiores suele disimular una autoestima lesionada, desquitándose así por haber sufrido una serie de experiencias agraviantes en su infancia, bien fuera a causa de la situación social en la cual se criaron (pertenecer a un grupo minoritario, ser pobre, aunque con parientes ricos), o debido a su propia posición individual. De acuerdo con el tema que aquí atañe, la filiación a un grupo puede suplantar esa experiencia olvidada por su connotación penosa, mas al aclararse los problemas relativos a la humillación, reaparecen en la conciencia.

Teniendo en cuenta lo anterior, es muy posible que los independentistas catalanes se aferren aún más a su idea de emancipación, tras el oprobio de ver a su presidente detenido por cargos que parecen haberse quedado sin piso frente a la justicia alemana.

No obstante, Brock y Atkinson (2008) referencian estudios basados en la experiencia, en los que la relación entre vías grupales coadyuvaría al fortalecimiento de este argumento y otros que invalidan tal evidencia. Por ejemplo, citan a Blank (2003) quien a través de estudiar empíricamente la identidad nacional de las antiguas República Federal de Alemania y República Democrática Alemana encontraron que la relación entre la autoestima y las vías intergrupales es bastante débil; pero también se refieren a Crocker y Schwartz (1985), quienes a través de estudios con grupos pequeños concluyeron que individuos con alta autoestima presentan mayor identificación con el propio grupo que aquellos cuya autoestima es baja. 
La necesidad de identidad y del pertenecer, son otras de las necesidades que identifican Brock y Atkinson (2008). Para ello referencian la teoría óptima de la distinción de Brewer y Campbell (1976), que sostiene:

Los seres humanos tienen dos motivos sociales poderosos: una necesidad por inclusión que motiva el intento por ser asimilado en una colectividad amplia e impersonal, y una necesidad opuesta de diferenciación que es satisfecha mediante el distinguirse a sí mismo de los otros. Como motivantes opuestos, los dos necesitan abrazarse mutuamente. Cuando una persona se siente desolada o separada de una colectividad, la necesidad de inclusión crece; por otro lado, la inmersión en una sociedad excesivamente amplia y no bien definida activa la búsqueda por diferenciación y distinción (Brewer y Campbell, 1976, pp. 21-22).

Las naciones sin Estado, cuya definición dada por Guibernau (1998) se mencionó al principio de este artículo, pueden servir para levar esta necesidad psicológica del individuo, coligada al nacionalismo colectivo. Aunque esta autora no considera dentro de su clasificación las agrupaciones indígenas, y menos las de Colombia y Ecuador, basta pensar en los casi 57000 indígenas kichwa de la Sierra-Otavalo en la vecina república de Ecuador, que son los mismos otavaleños de los cuales, según datos del censo de 2005, existen aproximadamente mil en Colombia. Ellos, aun estando en Estados nación diferentes, guardan un sentido de identidad y pertenencia perceptible con sus pueblos ancestrales kichwa andino de la sierra: su lengua, proveniente de la misma familia lingüística quechua; sus festividades y creencias; la vestimenta característica (anaco o falda larga de paño, blusa bordada con encaje y flores, el mamachumbe o correa mayor, acompañada de un cinturón más delgado denominado chumbi, la fachalina o pañolón de paño, fachalina de paño en el pelo, la combinación de collares amarillos con coral y cintas de colores para el pelo), y su alimentación (boda -especie de mazamorra de maíz-y el yamor o chicha hecha a base de siete tipos de maíz), entre otros rasgos culturales. Probablemente, su grado de cohesión y sus aspiraciones políticas se hayan visto y quizá se seguirán viendo fragmentadas con el paso de los años por la necesidad de inclusión y de mimetización en sociedades más amplias e impersonales, pero su necesidad de distinción y autoestima como grupo homogéneo que añora sus orígenes sigue viva.

La identificación se encuentra también en el psicoanálisis lacaniano, así lo anota Sedinger (2002, p. 48), que reconoce dos tipos de identificación: imaginaria y simbólica. La última es mimética; ocurre en el vínculo con el otro, a quien el sujeto toma como modelo para su identidad. Entre otras características, las identificaciones imaginarias se diferencian por entrañar la homogeneidad: patrocinan un tipo particular de colectivo o clase sobre la base de una semejanza entre sus miembros, la mayoría de las veces basada en una propiedad compartida.

La escala de necesidad de inclusión o diferenciación puede variar sustancialmente, y ello mismo le da espacios al cosmopolitismo; la teoría óptima de la distinción no descansa en la ya discutida necesidad de autoestima e identificación; por tanto, no necesariamente implica que la identificación nacional esté alimentada o cause la hostilidad contra los otros, o los no nacionales. 
La necesidad de tener significado y sentido en la vida también forma parte de lo que aquí se denominan "causas naturales del nacionalismo". Parafraseando a Brock y Atkinson (2008), se trata de una necesidad existencial que minimiza la incertidumbre; de no poseer dicho significado y sentido careceríamos de estabilidad y permanencia. Entre las alusiones que este par de autores hacen para profundizar en este punto está la postura de Festinger $(1950,1954)$, quien sostiene que las creencias de un individuo le proporcionan estabilidad y autoestima en la medida en que sean probadas, aceptadas y consideradas apropiadas por sus semejantes. Según la teoría del manejo del terror de Solomon, Greenberg y Pyszczyn (1991) referida también por Brock y Atkinson (2008), la identidad nacional puede prevenir que el individuo se enfrente a una especie de zozobra causada por una moralidad que percibe como única e individual, es decir, que no comparte con nadie más; dicha incertidumbre también puede ocasionarse por la posibilidad de eventos trágicos que vistos desde una posición efímera, personal y subjetiva desembocan en tal ansiedad; la persona decide entonces cambiar tal lectura, tan propia e íntima de la realidad, por una visión de nación que considera más duradera y estable, y que, por tanto, mejora su autoestima y reduce su ansiedad.

Un ejemplo de este tipo de necesidad la presenta Ortigueira (1963, pp. 478-479) cuya reflexión, refiriéndose a reacciones psicopatológicas y actitudes políticas autoritarias se parafrasea a continuación: "Efectos de desorga- nización" que dejan como secuelas la inflación y desocupación; las cuales afectan a los individuos produciéndoles sentimientos de inseguridad $\mathrm{y}$ angustia que los hace sentir frustrados, sin oportunidades para salir adelante. Así, el individuo se siente aislado y excluido del proceso social, soportando una autopercepción de prescindencia y nimiedad. Eso conlleva desarraigo y quiebra de la solidaridad social y presiona a los hombres a conducirse como enemigos. Si a ello se suma el tránsito acelerado de un medio cultural al otro (en el caso de los inmigrantes de los campos a la urbes) $)^{2}$, aunado a escenarios políticos y sociales de constante inestabilidad, desembocan en realidades sociológicas conflictivas y con excesivas fricciones en el proceso de ajuste. Se estructura así una personalidad en la que la angustia y la hostilidad conforman una estrecha relación causal, ya que estas antipatías son una reacción defensiva inconsciente ante las circunstancias desacostumbradas de la realidad objetiva, $y$ frente a las que la persona no se encuentra preparada para actuar de forma apropiada. "Aún más, si la hostilidad es reprimida puede llegar a provocar angustia, generándose así un perfecto circuito cerrado" (Horney, 1993, p. 41). En medio de tales ambientes de inseguridad generalizada, los sujetos afectados proyectan simbólicamente su animosidad en personas o entidades que se presentan como fines sustitutivos del conflicto verdadero (élites, políticos, imperialismo, judaísmo). Aparece así el rechazo, la violencia y las ideologías autoritarias particulares de cada momento. Tal es el caso del estalinismo, el nazismo y el fascismo.

2 La concentración urbana, el déficit habitacional, el subempleo, la inflación. 
Se analiza brevemente uno de estos fenómenos de la historia internacional, a la luz de tener significado en la vida, de minimizar la zozobra que nace de tener creencias únicas y personales, prefiriendo filiarse a causas nacionales. El estalinismo nació en el seno de la segunda revolución rusa (1917), un poco antes de que Stalin sucediera en el poder a Lenin en 1924. La ideología marxista, aunque latente en los discursos de Lenin y Stalin, pareció pasar a un segundo plano al menos en lo que hacía referencia a tres de los principios de la Tercera Internacional Socialista: primero, suponía que el proletariado era una fuerza internacional y no como ocurrió con el estalinismo, que por fuerza o conveniencia, terminó por constituir una causa internacional en un interés nacionalista, pues ya para 1917 era evidente que el comunismo no iba a tener un espacio significativo en Europa occidental ni en el resto del mundo, luego la antigua Unión Soviética no iba a tener el respaldo de las grandes potencias para sostener este sistema. Stalin se encontraba solo en la esfera internacional queriendo mantener el comunismo.

Segundo, no debería haber lugar a la mencionada autodeterminación de los pueblos (que tanto Lenin como Stalin invocaron para mantener la revolución bolchevique), pues la revolución proletaria tenía un carácter mundial, y tercero,

La revolución rusa de 1917 debía someterse a los intereses del proletariado internacional, y no como sucedió, bajo presión de Lenin y los bolcheviques, que consiguieron someter la Internacional a los designios e intereses de la revolución nacional rusa y de su capitalismo de Estado. Bordiga denunciaba esto como "inversión de la pirámide" -esto es la Internacional sometida a los intereses nacionales del PC de Rusia(Guillamon, 2008).

Este suceso, y más aún la aparente complicidad con los masivos asesinatos que se vieron acrecentados con "la purga" tras el homicidio de Serguéi Kirov en 1937; dejan entrever que dentro de una nación plurinacionalista, como lo era la Rusia de ese entonces, hubo un esfuerzo colectivo por buscar una relativa estabilidad, un significado, garantizar la existencia y permanencia de un régimen político, más allá de las creencias personales de muchos bolcheviques y antibolcheviques que testeaban sus propios juicios frente a los dogmas nacionalistas superiores que les imponían. La historia señala a Stalin y sus camaradas como los líderes del siglo xx, cuya barbarie y brutalidad son ampliamente rechazadas.

Las necesidades biológicas. Enraizadas en la teoría de la evolución, las necesidades biológicas no deben ser ignoradas. Según este argumento, todos los grupos tienen mecanismos de selección natural y ello puede justificar el nacionalismo. Parafraseando a Brewer (1999, p. 433) los seres humanos nos caracterizamos por cierta necesidad de interdependencia, compartimos información, afecto, recursos, ayuda, etc. Pero asimismo, esperamos que tal intercambio sea recíproco, el altruismo indiscriminado no es efectivo para la propia supervivencia; por ello damos prioridad a nuestro grupo y de esta manera se justifica el nacionalismo o lo que aquí se denomina "favoritismo por los míos". Tales intercambios son el resultado de miles de años de selección de los individuos, en aras de maximizar su propia subsistencia. 


\section{LOS MOTIVANTES INDIVIDUALES DEL COSMOPOLITISMO}

Así como se han identificado algunas necesidades psicológicas del ser humano que pueden satisfacerse con posturas nacionalistas, corresponde ahora estudiar aquellas aspiraciones de las personas que serían complacidas con actitudes más cosmopolitas.

\section{La necesidad de cooperación}

Si bien se ha estudiado aquí que los individuos tienden a colaborar más con los de su grupo por cuestiones de identidad y de buscar inconscientemente proyectar en otros, que no se consideran semejantes, las propias carencias, también es cierto que al individuo se le puede otorgar el crédito de desear ser bondadoso y altruista; de cooperar con otros distintos a su grupo, de identificarse con propósitos que favorezcan a ajenos; de hacer la elección correcta en pro de otros, y más aún si esto no compromete la propia identidad nacional. "Tenemos que aprender por nosotros mismos y después, enseñar a los desesperados que en realidad no importa que no esperemos nada de la vida, sino si la vida espera algo de nosotros" (Frankl, 1991, p. 62).

De hecho Brock y Atkinson (2008), haciendo referencia al estudio de Brewer y Brown (1998), insisten en que si bien la hostilidad entre grupos puede ser disparada en condiciones de competencia, la homogeneidad con identidades superiores (trasnacionales) puede ser avivada dando los estímulos apropiados en los cuales se irá profundizando. La investigación de Nonprofit Tech for Good "Tendencias de la donación económica a nivel mundial”, publicada en septiembre de 2017, en la que se encuestaron más de cuatro mil donantes y que se resume en la página web de Semántica Social, ayuda a dar fuerza al argumento de que como seres humanos necesitamos ser bondadosos con otros diferentes a las personas de nuestro entorno. Un número importante de los donantes provienen de Estados Unidos, Canadá y Reino Unido, todos países desarrollados que no conocen siquiera a quiénes irán dirigidas sus ayudas; más aún, el 60\% de los donantes prefieren hacer donativos por internet.

Las donaciones parecen estar repartidas en muchas causas de manera semejante, aunque cabe señalar dos datos: el 9\% van destinadas a servicios humanos, y le siguen de cerca, con $8 \%$, las causas de derechos humanos.

En cuanto a la periodicidad, $54 \%$ de los donantes son no esporádicos, de estos, el $82 \%$ son donantes mensuales, y tan solo $9 \%$ son donantes anuales.

La motivación del donante suele ser la esperanza y la empatía, razón por la cual las festividades religiosas contribuyen a incrementar donativos... El $45 \%$ de los donantes realiza donaciones fuera del país, destinadas a proyectos de cooperación al desarrollo... El 66\% de los donantes han trabajado como voluntarios en entidades sin ánimo de lucro en los últimos 12 meses. El $97 \%$ piensa que ser voluntario ha sido una experiencia transformadora (García, 2017, negritas fuera de texto).

Por otro lado, Deschamps y Brown (1983), también citados por Brock y Atkinson, señalan que facilitar la cooperación intergrupal es más sencillo cuando las tareas o la división del trabajo es más específica dentro de los grupos. 
Esto es entendible en la medida en que se obliga a una mayor comunicación y a un mayor intercambio. Lo anterior conduce a otras necesidades que pueden identificarse en el ser humano, como veremos a continuación.

\section{La necesidad del intercambio, de integrar lo ajeno y la curiosidad por lo distinto}

Si bien este tipo de anhelos con seguridad se han incrementado en los últimos años por la globalización, la proliferación de los medios de comunicación y de las redes sociales, es de reconocer que la necesidad de intercambio, de integrar lo ajeno y la curiosidad por el otro se pueden reconocer desde siglos atrás, incluso teniendo en cuenta las barreras lingüísticas, culturales y geográficas: los indígenas muiscas en la historia prehispánica intercambiaban sal por otro tipo de bienes; Europa comerciaba especias con las Indias, y en la historia moderna basta reflexionar sobre el papel de las corporaciones y megacorporaciones:

Si usted conduce un vehículo Ford Escort, es probable que su transmisión haya sido hecha en Japón, su sistema eléctrico en Taiwán, el mecanismo de abrir la puerta en México, sus amortiguadores en España, sus frenos traseros hayan sido ensamblados en Brasil, su dirección en Gran Bretaña y muchas otras partes en diversos países del mundo... la industria automotriz se ha globalizado más y por supuesto se ha complicado más [esta industria]... y otras tendientes a capturar una mayor participación en los mercados globales... se han puesto al rojo vivo con la celebración de alianzas entre las fronteras trasnacionales (Pearson y Rochester, 2004, p. 10).
Pero el intercambio, no necesariamente tiene que ser de bienes, son relevantes también las ideas.

\section{La necesidad de intercambiar ideas, de comunicación, y de aprender de los otros}

"El reconocimiento de la perspectiva del otro es la clave para el cosmopolitismo y tiene por ello poco sentido hablar de cosmopolitismo en ausencia de este reconocimiento" (Delanty, 2008, p. 38). El individuo tiene la necesidad de renovarse a sí mismo, y puede lograrlo a través de reconocer en el otro una fuente impuesta o no de conocimiento y crecimiento.

Por ejemplo, la movilidad laboral y académica del mundo actual y las diásporas que han acaecido en la historia del mundo (la salida del pueblo judío de Egipto hacia la tierra prometida, y luego hacia Estados Unidos y Palestina después de la segunda guerra mundial, y más recientemente las de los kosovos a Europa Occidental durante la guerra de 1999) implican enfrentar un proceso de asimilación con la(s) cultura(s) receptora(s), que puede o no ser traumático en la medida en que el individuo tenga la habilidad de mimetizarse, de leer costumbres y adaptarse a ellas.

Respecto de la responsabilidad del individuo de hacer un proceso de ajuste tranquilo a un mundo diferente, vale la pena traer a colación la reflexión del psiquiatra austriaco de origen judío Viktor Frankl, quien sobrevivió durante la segunda guerra mundial, entre otros, a dos de los más temidos campos de concentración, Dachau y Auschwitz, experiencia que sintetizó en su libro El sentido de la vida (1991): 
Al declarar que el hombre es una criatura responsable y que debe aprehender el sentido potencial de su vida, quiero subrayar que el verdadero sentido de la vida debe encontrarse en el mundo y no dentro del ser humano o de su propia psique, como si se tratara de un sistema cerrado (Frankl, 1991, p. 63).

Por supuesto, los procesos de adaptación exitosos no solo dependen del individuo, sino también de las posibilidades y el buen ánimo de las colectividades receptoras de aceptar y quizás potencializar su modus vivendi con los conocimientos, el emprendimiento, las ideas y la fuerza laboral de los inmigrantes. Esto lleva a reflexionar sobre el anhelo de recategorización social.

\section{La necesidad de recategorización social}

Según Brock y Atkinson (2008, p. 175) existe evidencia de que la cooperación puede engendrar recategorización social, y ello también puede leerse como una necesidad, si se analizan los fenómenos que han estimulado las diásporas de millones de asiáticos e hispanoamericanos a Estados Unidos y Canadá en busca del "sueño americano", así como la migración de kosovos hacia Austria, Escandinavia y Alemania desde 2015 para lograr el "sueño alemán”, o la entrada de venezolanos a Colombia y otras latitudes de Suramérica en los últimos dos años.

Por otro lado, la recategorización social la obtiene también un individuo por su grado de filantropía, y por su capacidad de enrolarse en causas que beneficien a la humanidad en general, lo que podríamos renombrar o extender al deseo de trascender.

\section{La necesidad de trascender, de dejar huella en el mundo}

Es evidente que a este tipo de necesidad puede semejarse la necesidad de cooperación; no obstante esta sería una clase de anhelo más existencial. El citado psiquiatra Viktor Frankl (1991, p. 58), profundizó en las necesidades existenciales del ser humano, asegurando que hay tres formas distintas de utilizar el vocablo existencial: primero, para hacer referencia a la propia existencia; segundo, con el fin de aludir al sentido de la existencia y, finalmente, para puntualizar en el afán de encontrar un sentido concreto a la existencia personal, en otras palabras, la voluntad de sentido. La frustración existencial se puede también resolver en neurosis. Para este tipo de neurosis, la logoterapia, cuyo pionero es el mencionado doctor, ha adoptado el término "neurosis noógena", que difiere de la neurosis descubierta por Freud, pues mientras la de Frankl tiene su origen en frustraciones existenciales, la de Freud descansa más en deseos inconscientes no satisfechos.

El miedo a morir sin perpetuar el nombre, o sin haber hecho una contribución a la preservación de la vida, el mismo eros o instinto de vida descubierto por Freud, puede hacer que el individuo se matricule en causas más cosmopolitas que nacionalistas. Problemas como los que afectan el medio ambiente (calentamiento global, deforestación, subsecuentes problemas de agua), la escasez energética, la expansión demográfica, la miseria en latitudes ajenas son realidades que obligan al hombre a tomar conciencia de su propias limitaciones y responsabilidades con la humanidad, y por ello a que esté ávido de ayudar a otros. 
Frankl (1991, p. 56) sostenía: "La búsqueda por parte del hombre del sentido de la vida constituye una fuerza primaria y no una 'racionalización secundaria' de sus impulsos instintivos". Puede pensarse entonces, que instintivamente el hombre necesita ser coherente con sus valores morales y necesita aplicarlos a través de afiliarse a una buena causa que no solo favorezca su entorno directo (a los míos), sino que además facilite la vida de los otros.

Este sentido es único y específico en cuanto es uno mismo y uno solo quien tiene que encontrarlo; únicamente así logra alcanzar el hombre un significado que satisfaga su propia voluntad de sentido... Hace unos cuantos años se realizó en Francia una encuesta de opinión. Los resultados demostraron que el $80 \%$ de la población encuestada reconocía que el hombre necesita "algo" por qué vivir. Además, el 61\% admitía que había algo, o alguien, en sus vidas por cuya causa estaban dispuestos incluso a morir. Repetí esta encuesta en mi clínica de Viena tanto entre los pacientes como entre el personal y el resultado fue prácticamente similar al obtenido entre las miles de personas encuestadas en Francia; la diferencia fue solo de un $2 \%$. En otras palabras, la voluntad de sentido para muchas personas es cuestión de hecho, no de fe (Frankl, 1991, p. 56).

Analizándolo así, los universalistas encontrarían un adalid que parte de lo más intrínseco del ser humano:

Esta es una noticia alentadora para los cosmopolitas que necesitan estrategias de transición: podemos mantener algo de la zona de confort familiar [en esferas nacionales], por así decirlo, mientras trabajamos para extender esa zona de confort al mismo tiempo [a esferas más universales] (Brock y Atkinson, 2008, p. 175).

Antes de concluir es importante tomar en cuenta que el cosmopolitismo y el nacionalismo elevan el nivel de las emociones y los afectos. Según Warf (2012) las emociones primarias del nacionalismo son el orgullo y el miedo, las del cosmopolitismo son la empatía y el respeto. Si bien se trata de emociones muy diferentes, en opinión de quien escribe este artículo coexisten en el individuo y en la psiquis colectiva de los pueblos. Puede que en ciertos momentos de la historia del mismo país, o en momentos similares en diferentes latitudes se aviven más las llamadas emociones nacionalistas y en otros las cosmopolitas.

Hoy en día y dada la interdependencia financiera que han facilitado las telecomunicaciones, puede que un país, por causas nacionalistas piense dos veces antes de declararle la guerra a otro, pues ello significaría el derrumbe de su moneda, o de acciones en la bolsa de las empresas nacionales que, como se anotó, cada vez son más transnacionales. La interdependencia financiera y económica pueden ser, y son de hecho, elementos de persuasión contra la guerra si se compara el mundo de antes de la invención del telégrafo (1886) que permitió que se dieran las primeras transacciones financieras entre Estados Unidos y el Reino Unido, o antes de la primera guerra mundial (1914), e incluso del período entre esta y la segunda guerra mundial.

Pareciera entonces que el cosmopolitismo, que pudiera leerse fácilmente con el paradigma idealista, también pueda ser entendido 
desde ópticas más neorrealistas. Y el nacionalismo sería propio de la manera de los realistas de comprender el mundo.

\section{CONCLUSIONES}

Se han discutido las "causas naturales del nacionalismo", es decir, las necesidades psicológicas que justifican el nacionalismo: "el favoritismo por los míos", las necesidades de autoestima y automejoramiento, de identidad y del pertenecer, de tener significado y sentido en la vida y las necesidades biológicas.

La guerra entre pakistaníes e indios en 1971 ejemplifica "el favoritismo por los míos", pues estos apoyaban en sus fronteras a los que identificaban como propios: la India a la población bengalí y Pakistán a los punyab. El enfrentamiento dejó como ganador a los bengalíes convirtiendo a Pakistán oriental en lo que hoy se conoce como el Estado de Bangladesh. En este orden de ideas, el nacionalismo y la necesidad psicológica de favorecer a los míos llevada al colectivo, sería a su vez el origen y una consecuencia de la lucha por los recursos escasos, como el territorio, en este caso el antiguo Pakistán oriental.

El cataluñismo, por su parte, representa la necesidad de automejoramiento y autoestima y con ello la necesidad de afiliarse a un grupo, como la nación sin Estado de Cataluña, cuyas ansias de emancipación se incrementaron desde 2006. Y puede que los catalanes se aferren más a esta idea tras la salida de Mariano Rajoy de la presidencia del gobierno español y del Partido Popular, colectividad que siempre se ha opuesto a tales ambiciones independentistas, la recuperación del poder por parte de quienes se han mostrado más consecuentes con ese anhelo, el Partido Social Obrero Español (PSOE) en cabeza de Pedro Sánchez, y la puesta en libertad de Carles Puigdemont en Alemania.

La necesidad de identidad y de pertenecer, el anhelo de un individuo de afiliarse a un grupo para mejorar su autoestima, para distinguirse de una gran masa, pero a su vez ser asimilado por un grupo, puede ejemplificarse con los indígenas kichwa (u otavaleños) de la Sierra, que comparten costumbres y tradiciones aunque no un territorio definido en Colombia, adquiriendo un estatus de nación sin Estado, pues provienen de Ecuador y hoy se encuentran presentes en el territorio nacional. La cohesión y las aspiraciones políticas de los que habitan en el país puede que sean nulas o muy bajas por el deseo de inclusión y de mimetización en una sociedad más extensa e impersonal, sin embargo, aunque no son hostiles con quienes no pertenecen a su comunidad, su necesidad de distinción y autoestima como grupo homogéneo que añora sus orígenes, se sigue evidenciando en su indumentaria y en la forma de obtener su sustento (venta callejera de tejidos, bordados, etc.).

El estalinismo mantuvo la ideología marxista en su discurso después de la revolución bolchevique, aun cuando se contradijeran los principios de la Internacional Socialista, pues era claro que el comunismo no iba a tener acogida, al menos durante algún tiempo, en el resto de Europa. El fin de mantener tal oratoria viva en la Unión Soviética era el de cohesionar, mantener causas comunes evitando que las personas perdieran el significado de sus vidas, 
y para minimizar su incertidumbre, que podría surgir de tener creencias únicas y personales que no fueran aprobadas por la nación.

También se ha hecho un esfuerzo por construir una enumeración de anhelos que pueden ser satisfechos con posturas cosmopolitas: la necesidad de cooperación, de intercambio, de integrar lo ajeno y la curiosidad por lo distinto; la necesidad de cambiar ideas, de comunicarse, de aprender de los otros, de recategorización social y de trascender, de dejar huella en el mundo.

El deseo del ser humano de ser altruista, de ser bondadoso y de dar un significado a la vida, de colaborar con grupos así no sean los propios se evidencia en las donaciones a causas que se consideran justas.

La globalización y propagación de los medios de comunicación y de las redes sociales facilitan satisfacer la necesidad del intercambio, de integrar aquello por lo que se siente gusto y curiosidad, pero pertenece a los otros. El comercio de sal en culturas prehispánicas, o de especias entre Europa occidental y las Indias son clara evidencia de que esta necesidad ha existido desde tiempo atrás, y la forma como funcionan las corporaciones y megacorporaciones modernas son un claro ejemplo de que estos anhelos se han profundizado con el tiempo.

Pero el intercambio de bienes y servicios no es lo único que satisface al hombre. También renovar las ideas, adquirir conocimiento a través del otro es importante, pues se reconoce que ese otro tiene sentido y que puede aportar a la comunidad. La movilidad académica y laboral del mundo de hoy son claro ejemplo de ello. De la misma manera, las migraciones y diásporas de distintos pueblos desde muy antiguo y a lo largo de la historia de la humanidad, también evidencia la necesidad de intercambio cultural y más aún de recategorización social. Con respecto a esto último y a la adaptación que las migraciones suponen, es importante concluir que para que estas sean exitosas, tanto para el individuo que llega como para la comunidad que lo recibe, es fundamental que ambos desplieguen sus habilidades para potenciar ese contacto a su favor.

El miedo a morir sin perpetuar el nombre o sin haber hecho una contribución a la preservación de la vida, el mismo eros o instinto de vida descubierto por Freud, puede hacer que el individuo se matricule en causas más cosmopolitas que nacionalistas. Problemas como los que afectan el medio ambiente, la escasez energética, la expansión demográfica, la miseria son realidades que obligan al hombre a tomar conciencia de su propias limitaciones y responsabilidades con la humanidad, y lo predisponen a ayudar a los otros. Por ello se habla de necesidades existenciales del hombre, de encontrarle sentido a la vida; filantropías que caben más en una visión cosmopolita del mundo y que también lo recategorizan socialmente, obligándolo a tomar conciencia de sus propias limitaciones y deberes no solo con su comunidad, sino también con la humanidad.

Tal como ocurre en el mundo académico, debe reconocerse que un grupo de necesidades del individuo puede entrar en tensión con el otro; pero la misma fuerza que las hace repelerse entre sí, también puede servir como elemento cohesionador o balanza que equilibra la psiquis del individuo y de los grupos. 
Así, por ejemplo, para que la persona sienta la necesidad de favorecer a otros, debe primero identificar a los propios; no hay razón para que la cooperación con los suyos le impida colaborar con otros o con la humanidad en general.

La proyección que se hace de carencias propias sobre los no semejantes, "los otros", es compensada por el anhelo de cooperar y trascender. La necesidad de autoestima y automejoramiento (satisfecha mediante posturas más nacionalistas) también se puede conseguir a través del suplir anhelos cosmopolitas: el conocimiento, el aprendizaje, la comunicación y el intercambio con el otro. Y, por supuesto, la recategorización social a la que se le abre mayor espacio con el cosmopolitismo, resultaría muchas veces reforzando la autoestima y el automejoramiento que es una "causa natural del nacionalismo". Luego, no hay nada antiético entre un grupo de necesidades y otro, se pueden suplir los afanes psicológicos del cosmopolitismo sin poner en riesgo las avideces del nacionalismo.

Tanto el nacionalismo como el cosmopolitismo generan emociones, para el primero las más fácilmente identificables son el orgullo y el miedo, en tanto que para el segundo son la empatía y el respeto.

El nacionalismo se ajusta a la manera de comprender el mundo de los realistas. El cosmopolitismo tradicionalmente se lee bajo el paradigma idealista, pero dada la globalización de capitales y lo que ello significa como elemento persuasor de las guerras, al menos entre Estados, también puede ser entendido desde ópticas más neorrealistas.

\section{REFERENCIAS}

\section{Trabajos citados y efectivamente consultados}

Brock, G. y Atkinson, Q. (2008). What can examining the Psychology of Nationalism Tell Us About Our Prospects for Aiming. Ethical Theory and Moral Practice, 11(2), 165-179.

Delanty, G. (2008). La imaginación cosmopolita. Revista CIDOB d'afers internacionals, Fronteras: Transitoriedad y dinámicas interculturales, 82-83, 35-49.

Frankl, V. (1991). El hombre en busca de sentido. Barcelona: Herder.

García, M. (18/09/2017). Semántica social. Recuperado el 6 de mayo de 2018, de Semántica Social [blog]: http://www.semanticasocial.es/2017/09/18/ tendencias-la-donacion-nivel-mundial/.

Gibernau, M. y Núñez, R. (1998). El futuro del nacionalismo de las naciones sin Estado. Universidad Nacional Autónoma de México, 60(1), 115-130.

Guillamon, A. (13/12/2008). ¿Qué fue el stalinismo? En Red-Libertaria.net. Recuperado el 1 de mayo de 2018 de https://red-libertaria.net/que-fue-elestalinismo/

Horney, K. (1993). La personalidad neurótica de nuestro tiempo. Barcelona: Paidós.

Kristeva, J. y Vericat, I. (1996). Freud: "heimlich/ unheimlich", la inquietante extrañeza. Debate feminista, 13, 359-368.

Ortigueira, R. (1963). La desintegracion, estado normal de países en desarrollo. Journal of Inter-American Studies, 5(4), 471-494.

Pearson, F. y Rochester, M. (2004). Relaciones internacionales. Santafé de Bogotá: McGraw -Hill.

Sedinger, T. (2002). Nation and Identification: Psychoanalysis, Race, and Sexual Difference. Cultural Critique (50), 40-73. 
Subercaseaux, B. (1993). Lo masculino y lo femenino en el imaginario colectivo de comienzos de siglo. Revista Chilena de Literatura (42), 245-250.

Warf, B. (julio de 2012). Nationalism, cosmopolitanism, and geografical imagination. Geographical Review, 102(3), 271-292.

\section{Trabajos citados y consultados}

a través de otras fuentes

Blank, T. (2003). Determinants of national identity in East and West Germany: an empirical comparison of theories on the significance of authoritarianism, anomie, and general self-e. Political Psychology, 24(2), 259-288.

Brewer, M. y Campbell, D. (1976). Ethnocentrism and intergroup attitudes: East African evidence. Beverly Hills: Sage.

Brewer, M. y Brown, R. (1998). Intergroup relations. En F. S. Gilbert (ed.). The handbook of social psychology, 2, 554-594.

Brewer, M. (1999). The psychology of prejudice: ingroup love or outgroup hate? Social Issues, 55(3), 429-444.
Crocker, J. y Schwartz, I. (1985). Prejudice and ingroup favoritism in a minimal intergroup situation: Effects of self-esteem. Pers Soc Psychol Bull 11(4): 379-386.

Deschamps, J. C. y Brown, R. (1983). Superordinate goal and intergroup conflict. Social Psychology 22(3), 189-195.

Festinger, L. (1950). Informal social communication. Psychological Review 57(5), 271-282.

Festinger, L. (1954). A theory of social comparison processes. Human Relat(7), 117-140.

Sherif, M. (1966). In common predicament: social psycology of intergroup conflict and cooperation. Boston: Houghton-Mufflin.

Solomon, S.; Greenberg, J. y Pyszczyn, T. (1991). A terror management theory of social behavior: the psychological functions of self-esteem and cultural worldviews. Academic Advances in Experimental Social Psychology, 24, 93-159.

Tajfel, H. y J. Turner (1979). An integrative theory of intergroup conflict. En Austin, W. y Worchel, S. (eds.). The social psychology of intergroup relations (pp. 33-47). Michigan: Universidad de Michigan.

Tajfel, H.; Billing, M. G.; Bundy, R. P. y Flament, C. (1971). Social categorization and intergroup behaviour. Eur J Psychool, pp. 149-178. 